\title{
What is shaping vulnerability to climate change? The case of Laamu Atoll, Maldives
}

\author{
Karen E. McNamara
}

The University of Queensland, Brisbane, Australia

karen.mcnamara@uq.edu.au

Rachel Clissold

The University of Queensland, Brisbane, Australia

rachel.clissold@uq.net.au

Annah Piggott-McKellar

The University of Queensland, Brisbane, Australia

a.piggottmckellar@uq.edu.au

\section{Lisa Buggy}

The University of Queensland, Brisbane, Australia

lisa.buggy@uq.net.au

\section{Aishath Azfa \\ United Nations Development Programme, Malé, Maldives aishath.azfa@undp.org}

\begin{abstract}
As climate change accelerates, it brings with it numerous challenges to society and the natural world. Concepts such as vulnerability have emerged as a way of trying to understand people's risk, despite there being a range of variables that can influence vulnerability and its temporal and spatial dimensions. Drawing from the well-known conceptualisation of vulnerability as a function of exposure, sensitivity, and adaptive capacity, this paper seeks to understand what variables are influencing and shaping vulnerability in Laamu Atoll, the Maldives, and produce a base of knowledge for future vulnerability reduction initiatives. Household questionnaires $(n=412)$ were used on Laamu Atoll to ascertain locals' perceptions of vulnerability based on livelihood resources, financial security, and climate-change experiences. Results show that peripherality, as a notion that describes the disparities between 'core' and 'peripheral' islands, is a key factor shaping vulnerability variables on Laamu Atoll. This has prompted an overarching recommendation for peripherality to be considered as a key dimension of vulnerability to climate change and an important consideration for existing and future human development and climate change policy and practice in Small Island Developing States.
\end{abstract}

Keywords: climate change, Maldives, peripherality, sea level rise, small islands, vulnerability https://doi.org/10.24043/isj.67

(C) 2019 - Institute of Island Studies, University of Prince Edward Island, Canada. 


\section{Introduction}

As climate-change risks cannot be reduced solely to a focus on hazards, vulnerability and its influencing role in risk reduction and mediating impacts has emerged as an important research field (Birkmann et al., 2013; Ribot, 2014). While a universal definition of vulnerability is lacking (Birkmann et al., 2013), there is broad consensus that vulnerability is an analytical tool that conceptualises a system's state of susceptibility to a stimulus or harm (see IPCC, 2014; Ribot, 2014). Vulnerability to climate change has been presented in earlier IPCC assessment reports $(2001 ; 2007)$ and other studies as a function of exposure, sensitivity, and adaptive capacity (Ford \& Smit, 2004; Füssel, 2007; Heltberg et al., 2009; Smit \& Wandel, 2006). Vulnerability and resilience have also been linked in the literature, although there are numerous contestations around the nature of the link (see Gallopin, 2006; Joakim et al., 2015). It may be broadly understood that a vulnerable system has lost resilience (Folke, 2005). Strengthening societal resilience to cope with and manage risks has therefore been highlighted as central to understanding and reducing vulnerability (Ford \& Smit, 2004). Measures to reduce vulnerability to climate change, however, have too frequently focused on hazards as an external threat while neglecting the root causes of vulnerability to the hazard (Kelman, 2014). These deep-seated and unresolved development challenges can manifest as poor resource access, inequity, and marginalisation (Kelman, 2014).

With this in mind, this paper intends to contribute towards a further understanding of vulnerability to climate change in the Maldives and provide a foundation for future vulnerability reduction initiatives that do not excessively focus on exposure to hazards. This is done through two key aims. The first is to examine what factors are contributing to overall vulnerability in Laamu Atoll, a southern coral atoll in the Maldives, through an analysis of households' perceptions on three thematic areas: access to and quality of livelihood resources, financial security, and climate-change experiences. This study is thereby focused on the extent to which households perceive vulnerability as opposed to being an objective risk assessment. Following on, the second aim involves understanding what shapes vulnerability in Laamu Atoll through an analysis of the three thematic areas against identity variables (i.e., age or gender), location, and income, which will provide an understanding of inequality's influence on vulnerability. As many existing studies in the Maldives focus on perspectives on and experiences of being exposed to climate hazards (e.g., Arnall \& Kothari, 2015; Becken et al., 2011; Shakeela \& Becken, 2015), this study will add to the existing literature by also exploring deep-rooted challenges that affect sensitivity and adaptive capacity. Moreover, by focusing on Laamu Atoll, this study will provide deeper insight into a more localised vulnerability context as opposed to the national scale (e.g., UNDP, 2014) or focusing on a particular sector such as tourism (e.g., Becken et al., 2011; Shakeela \& Becken, 2015).

This study's focus on Laamu Atoll is important as the Maldives is one of the world's Small Island Developing States (SIDS), which are largely perceived to be universally disproportionately vulnerable to climate risks (Brooks et al., 2005; Nurse et al., 2014). SIDS encompass 58 island states and are dispersed across four key regions: the Caribbean, Pacific, Indian Ocean, and West Africa (UN-OHRLLS, n.d.). Many SIDS, including the Maldives, are archipelagic which means they are comprised of a group of islands (Stratford et al., 2011). This focus on the Maldives is therefore also important as archipelagos have become an increasingly relevant conceptual tool that enables exploration of a previously neglected nexus of relations: 'island and island' relations rather than historically dominant 'land and water' or 'island and continent/mainland' relations (Stratford et al., 2011, p. 115). The Maldives and other SIDS are also comprised of atolls which are rings of coral reefs that enclose a lagoon with islands around the rim (Barnett \& Adger, 2003). For simplicity, this paper will use the term 'islands' as a general term to refer to individual islands as well as islands as part of atolls or archipelagos, unless specifically referring to Laamu Atoll which is the focus of this paper. 
Although there is extensive heterogeneity across these island nations, many SIDS also have commonalities (a concept that is occasionally referred to in the literature as 'islandness'), which contributes to higher levels of vulnerability (Ghina, 2003; Nurse et al., 2014; Pelling \& Uitto, 2001). This small island vulnerability is dependent on a range of environmental and socioeconomic pressures that contribute to and characterise exposure, sensitivity, and adaptive capacity. The next section will discuss the vulnerability of SIDS according to these three tenets and justify the framework for analysis employed for this study. This will be followed by a brief description of the study site and methods employed, and the remainder of the paper will discuss the factors that are contributing to and shaping vulnerability to climate change in Laamu Atoll.

\section{Literature review}

\section{Vulnerability of Small Island Developing States}

Exposure describes the extent, degree, and duration to which the 'exposed unit' (i.e., people, households, or an entire community) exists within the range of a hazard event and could be adversely affected (Birkmann et al., 2013; IPCC, 2014). Therefore, exposure is largely dependent on the system's location, geography, and 'level' of climate change (Füssel \& Klein, 2006). The location of SIDS in climatologically hazardous zones, for example, is a key contributor to SIDS' climatic exposure (Betzold, 2015; Encontre, 1999; Nurse et al., 2014). Key climatic and oceanic drivers of change that SIDS' geography exposes them to include tropical cyclones, drought, and storm swell events, as well as air and ocean temperature variation, ocean chemistry, rainfall, wind strength, sea levels, and wave climate (Nurse et al., 2014). Kelman (2018) identifies the three main sources of devastation for SIDS as sea-level rise (SLR) and ocean acidification, as well as changes in ecosystems which disrupt food and water supplies. The changes in frequency and intensity of the above are expected to narrow recovery time and cumulatively damage settlements, infrastructure, biodiversity, livelihood systems, and economic growth (Pelling \& Uitto, 2001). Exposure to climatic hazards is further influenced by structural characteristics of 'smallness' (in size and population), insularity, and remoteness among SIDS (Deidda, 2016; Nurse et al., 2014). Many islands have low elevations which increases susceptibility to coastal erosion, inundation or flooding, and other extreme events (Ghina, 2003).To avoid depoliticising underlying development challenges, it is important to shift focus away from these external threats and explore the underlying development challenges (Kelman, 2014) which can emerge through discussing sensitivity and adaptive capacity.

The notion of sensitivity denotes the degree to which a system is affected by climate change (whether adversely or beneficially) and is often dependent on intrinsic and contextual conditions (Birkmann et al., 2013; IPCC, 2001). A key aspect that contributes to SIDS' sensitivity is the higher risk of economic instability (Encontre, 1999; Pelling \& Uitto, 2001). Due to the smallness and remoteness of many islands, the capacity of SIDS to exploit novel trading opportunities and elevate competitiveness of existing economic activities at a global scale is limited (Deidda, 2016; Encontre, 1999). 'Structural rigidity' and reliance on a few export products occur as a result of, for example, narrow human and natural resource bases, and limited ability to enjoy economies of scale, as well as disproportionately high unit costs of producing, processing, transporting, and marketing commodities (Deidda, 2016; Encontre, 1999, p. 261). SIDS' economies not only lack diversification in their economic structure but also commonly specialise in climatesensitive sectors such as tourism and fisheries (Deidda, 2016; Nurse et al., 2014). A single event can therefore cause a disproportionate negative impact on the state's gross domestic product (GDP) and livelihoods (Encontre, 1999; Nurse et al., 2014). Some demographic trends in SIDS can also increase sensitivity. Urban primacy, for example, is a common characteristic of SIDS and involves a larger portion of the population residing in the largest urban areas (Fernandes \& Pinho, 2017). This places pressures on ecosystems and can result in overcrowding and poor housing conditions, as well as the growth of informal settlements which heighten sensitivity 
and event impacts (Fernandes \& Pinho, 2017; Pelling \& Uitto, 2001). This population concentration also corresponds to a concentration of key infrastructure which has emerged as another concerning feature, as one large event can result in significantly high losses (Ghina, 2003).

Adaptive capacity encompasses the ability or potential of a system to adjust to potential damage, to take advantage of opportunities, or respond to consequences (IPCC, 2014, 2007). The adaptive capacities of SIDS and their communities are limited by a range of factors which Betzold (2015) categorises under three key themes: lack of resources, institutional barriers, and awareness and perceptions. Local communities' adaptive capacities have also been undermined as a result of a growing dependence on donor knowledge and funding (Nunn, 2013). Key institutional barriers that have been observed among SIDS include poor linkages and coordination between government tiers that also limit communication with local communities (Betzold, 2015; Kuruppu \& Willie, 2015), lack of capacity among local leaders and institutions (Betzold, 2015) and poor enforcement (Nunn, 2009). Local populations (Lata \& Nunn, 2012) and private sectors (Kuruppu \& Willie, 2015) also tend to have poor awareness and understandings of climate change which curtails adaptive capacity by a lack of urgency for and value in anticipatory adaptation. Even among those with high rates of awareness and understanding, perceptions of risk are attenuated by several factors: the lack of clarity on the causes and consequences of changes, the pervasiveness of spiritual beliefs and church influence (Lata \& Nunn, 2012), and the prevalent perception that climate change is spatially and temporally distant (Arnall \& Kothari, 2015; Becken et al., 2011). To effectively reduce vulnerability, inter-territorial and confederate approaches to governance and policy across island states (Baldacchino, 2018), as well as tackling underlying development challenges (Kelman, 2014), may be critical.

As a process related to the insularity and remoteness of small islands (Deidda, 2016), the role of peripherality in the context of small islands vulnerability has also emerged (see Connell \& Lea, 1992; Fernandes \& Pinho, 2017; Nunn et al., 2014). The notion of peripherality was reflected in earlier, broad development models and theories such as Friedmann's (1966) CorePeriphery Model (see also Myrdal, 1957; Reynaud, 1981; Wallerstein, 1974) before emerging in the particular context of small islands. The Core-Periphery Model (Friedmann, 1966) captures the pattern in which outlying or peripheral islands embody rural characteristics that have a narrow range of opportunities and lower levels of access to basic services and infrastructure while 'core' centres have a greater concentration of opportunities and resources. The ensuing disparities in development, opportunities for economic and political power, and access to resources and services between core and the often disadvantaged peripheral islands can then shape the patterns of sensitivity and adaptive capacity within regions and sub-regions (Fernandes \& Pinho, 2017). Peripherality in small islands and archipelagos is particularly accentuated as a series of 'nested core-periphery relations' exist, which can result in a small island becoming a periphery to a periphery (where national cores are peripheral to an 'external core' beyond the Maldives as well) (Weaver, 1998).

Focusing in on the Maldives, this nation also has particular sensitivities to climate variability associated with the El-Niño Southern Oscillation climate system, increases in sea surface and air temperature, storm activity, ocean acidification and swells, coastal erosion (Ghina, 2003; Hay, 2013; Khan et al., 2002), and coastal flooding (Wadey et al., 2017). The Maldives is also comprised entirely of low-lying islands and the average ground level is only 1.5 metres above sea level which could mean extensive inundation by 2100 (Khan et al., 2002; Sovacool, 2012). Large ocean swells generated by distant extratropical cyclones have also, historically and more recently, affected the Maldives and caused major damage (Nurse et al., 2014). As identified by Malatesta \& Schmidt di Friedberg (2017), studies on climate vulnerability in the Maldives have focused discussions on climate and geomorphology (Hay, 2013), media discourse (Gay, 2014), and social and political implications (Arnall \& Kothari, 2015; Hirsch, 2015; Kothari, 2014; Sovacool, 2012). This study seeks to build on this work. 
There are, therefore, a range of socioeconomic and geographic features that characterise SIDS' exposure, sensitivity, and adaptive capacity. These unique features demonstrate how small islands are not microcosms of larger mainlands and thereby require separate, contextspecific vulnerability assessments (Deidda, 2016; Fernandes \& Pinho, 2017), a notion recognised by the appointment of SIDS as a 'special' case for environment and development in numerous major international agreements and agendas (e.g., UN, 2012, 1992). In this discussion, it is also important to note that although the dominant narrative of SIDS as vulnerable has resulted in a proliferation of national development plans in SIDS that incorporate climate-change scenarios and adaptation measures (Moore, 2010), this narrative also entails several negative consequences. This includes the production of generalised categories in global climate-change arenas, the establishment of a geographic imagery that posits islands as unresilient places requiring external assistance, and the institutionalisation of island vulnerability as undisputable for policy (Malatesta \& Schmidt di Friedberg, 2017). Challenges to these narratives have also emerged with Kelman (2018), for example, discussing counter-narratives that balance, contextualise, and nuance the assumptions made. This has necessitated a critical reflection and re-reading of existing narratives for island states (Kelman, 2018; Malatesta \& Schmidt di Friedberg, 2017).

\section{Framework for analysis}

Although frameworks and indices employed for measuring vulnerability can vary significantly, there is some consensus that vulnerability can be measured using a combination of exposure, sensitivity, and adaptive capacity (see Adger \& Vincent, 2005; Ford \& Smit, 2004; Smit \& Wandel, 2006; Weis et al., 2016), which have also been categorised as biophysical indicators (exposure) and socioeconomic indicators (sensitivity and adaptive capacity) (e.g., Brooks et al., 2005). As these are complex concepts that cannot always be directly measured, proxy indicators are often identified (Weis et al., 2016). Drawing from the literature on these three components, this study established a framework composed of three key thematic areas that act as proxies: access to and quality of livelihood resources, financial security, and climate-change experiences.

Although sensitivity and adaptive capacity can be influenced by a range of factors, many are manifestations of access to, availability and quality of, resources (Adger et al., 2003; Blaikie et al., 1994; McDowell \& Hess, 2012). Several vulnerability assessment studies therefore focus sensitivity and adaptive capacity indicators on resource access and availability (e.g., Nguyen et al., 2017; Weis et al., 2016). Enabling resource access can increase adaptive capacity and reduce vulnerability by, for example, forming the base from which adaptation actions can transpire (Adger \& Vincent, 2005; Blythe et al., 2015; McDowell \& Hess, 2012). Although livelihood resource and asset portfolios can include a range of options, this study focuses on access to and quality of three broad, climate-sensitive resource sectors: food, water, and health (see Füssel, 2010; Ludena \& Won Yoon, 2015; Moss et al., 2001). These livelihood resource sectors were selected for not only their insight into socioeconomic capacity (where higher scores are correlated with higher capacity), but also due to the simultaneous insight into sensitivity (see Füssel, 2010; Moss et al., 2001).

Financial security and associated economic resources were also identified as a primary proxy for adaptive capacity as it enables prompt absorption of and recovery from losses (Cutter et al., 2003; Marshall et al., 2014; Weis et al., 2016) through, for example, providing access to other resources, markets, and technology (Moss et al., 2001). This proxy has been considered an independent theme to aforementioned livelihood resources as it represents a group of indicators that are commonly found in other studies (see Blythe et al., 2015; McDowell \& Hess, 2012). Some of these indicators also provide insight into sensitivity as, for example, perceptions on finding and securing employment can indicate the level of transferable skills and ability to take advantage of other employment opportunities; characteristics that would lower livelihood impacts from climate change (Marshall et al., 2014). 
The final thematic area-experiences of climate-change impacts-predominantly indicates level of exposure but also provides insight into sensitivity and adaptive capacity. Several existing studies that employed participatory data collection processes explored observed and experienced changes or shocks to understand level of exposure (see Blythe et al., 2015; Lennox, 2015; Nguyen et al., 2017), a proxy that has also been employed in this study. This thematic area will also explore the impact of different stressors on livelihoods which can provide further insight into levels of sensitivity (see Blythe et al., 2015) as well as exposure (see Lennox, 2015; Weis et al., 2016). Difficulties coping with specific climate hazards and impacts will also be derived in order to provide further insight into levels of adaptive capacity (see Marshall et al., 2014) according to experienced hazard.

Several studies have recognised how inequality, as a product of intersecting social processes, can shape the susceptibility of certain groups and individuals to higher levels of harm and govern their capacity to respond (see Cutter et al., 2003; IPCC, 2014; Ribot, 1995). Characteristics of groups and individuals that have emerged as shaping vulnerability include socioeconomic status, immigration status, gender, ethnicity, age, occupation, location, education levels, and disability, among others (Cutter \& Finch, 2008; Cutter et al., 2003; Ribot, 2014, 1995; Wisner et al., 2004). In the Maldives, three variables were previously identified by UNDP (2014) to be key influencing factors: identity (i.e., age or gender), location, and income. These variables are also included in the framework to provide further insight into local vulnerability.

A range of other indicators for exposure, sensitivity and adaptive capacity could have been used in this study (e.g., Adger \& Vincent, 2005; Birkmann et al., 2013; Blythe et al., 2015; Brooks et al., 2005; Füssell, 2010; McDowell \& Hess, 2012; Marshall et al., 2014). Some studies, for instance, have assessed implemented adaptations to understand adaptive capacity (e.g., Lennox, 2015). Future assessments of vulnerability in Laamu Atoll and elsewhere in the Maldives and beyond should consider other proxy indicators and expand on the ones selected.

\section{Methods and study site}

This study contributes to a much larger project being piloted in Laamu Atoll, called Low Emission Climate Resilient Development (LECReD). This project is being delivered by a consortium of United Nations programs and agencies to ensure that local development planning evolves from stand-alone action plans to strategic, climate-smart, investmentmobilising, and evidence-based tools. Laamu Atoll was selected due to its range of lowemission development opportunities, coupled with its vulnerability to a host of climatechange impacts (UNDP, 2013). Understanding baseline vulnerability to climate change was a key component of this project.

Questionnaires were selected as the main method for this study as they can provide valuable insights into socioeconomic trends as well as people's experiences, attitudes, and values. They enable the collection of a large sample size across a broad geographical area and dispersed population in a shorter time than qualitative techniques (McGuirk \& O'Neill, 2016). The questionnaire ascertained data on socio-demographics of respondents, livelihood activities, livelihood resources, and perceptions of a changing climate and experiences of such. For livelihood resources, six core indicators based on the quality of and access to water, food, and health were selected and measured using a Likert scale $(1=$ very poor, $2=$ poor, $3=$ fair, $4=$ good, $5=$ very good). The likelihood of shortages in food and water were also measured through questions around past experiences. Five key financial indicators were used to explore households' financial security: monthly household income, income satisfaction, money for emergencies, and access to financial safety nets from community leaders, as well as ability to source and secure employment. Household income was measured according to four income brackets (less than MVR 4,999, MVR 5,000-14,999, MVR 15,000-24,999, and more than 
MVR 25,000; 1 USD=MVR 15.5). Income satisfaction was measured through asking respondents to select one of four options: 'income is not adequate for our needs' (score $=1$ ), 'it is difficult to live with our current income' $(=2)$, 'our income is adequate for our needs' $(=3)$, and 'we live very comfortably with our current income' $(=4)$. The final three financial indicators were based on respondents' extent of agreement $(1=$ do not agree to $5=$ strongly agree) to the following statements: 'my household has enough money if emergencies arise in the future', 'our community leaders provide us with economic safety nets if our household is struggling to meet its needs', and 'finding and securing employment is a challenge for our household'. Climate-change experience was measured through questions on whether respondents observed the climate changing over time and whether changes to livelihoods as a result of climatic changes were noticed. More detailed responses on specific climate hazards and impacts experienced were also collected through asking respondents to rate $(1=$ low to $3=$ high) the degree of negative impacts on households and the rate of difficulty of coping with hazards. All data collected under these three thematic areas were then analysed according to previously identified characteristics that shape vulnerability-gender, age, marital status, education, household composition, ethnicity, income, and geography-to ascertain if, and how, these characteristics might be shaping these key vulnerability indicators.

The questionnaire was focused at the household level given that significant data gaps exist at this scale. To administer the household focus, questionnaires were focused on surveying individuals over 18 years old who were considered head of the household. As an attempt to acquire a gender-balanced sample size, data collectors asked if either the male or female head of household was available to be surveyed. With facilitation from UNDP staff, the atoll council and island councils organised the collection of the questionnaires across all islands in Laamu Atoll in 2016. The councils organised for 24 data collecting teams (consisting of two people each) across the atoll. The data collectors received one-day training where the questionnaire and a phone app were discussed and piloted. The 'QuickTapSurvey' app, which was set up by UNDP staff, was used for inputting responses. At the end of each day, inputted data was uploaded into the app's cloud storage and UNDP were then able to access the data.

The sample size for the questionnaire was determined for each of the islands based on the number of registered households using the 2014 Census data, as well as the desired confidence interval (set at 15\%) and confidence level (set at 95\%). Using a sample-size calculator, the required sample size (ranging between 22 and 41 questionnaires) for each of the data collection sites or islands was determined, and this was met. In total, 412 questionnaires were collected, which was slightly above the sample size required. Purposeful sampling was then used to select the households to participate as this elevates the likelihood of higher response rates (McGuirk \& O'Neill, 2016). This was done by dividing the total number of households by the number of questionnaires to be collected in each island (e.g., for Maavah Island, 490/39 yielded 12 which indicated that every $12^{\text {th }}$ household would be selected to participate) (see Patton, 2002). A household registry from the island councils was used to systematically select the households to participate and if a household declined or was absent, the next household was selected.

The questionnaire was in English and verbally translated into the local language (Dhivehi) by the data collectors. While there are a number of challenges associated with the translation of research tools (e.g., equivalent semantics in Behling \& Law, 2000), this was necessary to avoid an English-speaking bias. The questionnaire was then coded and analysed using the Statistical Programme for the Social Sciences (SPSS, Version 22). Means, percentages, and frequencies were used to summarise the quantitative data and a number of tests were undertaken to analyse the data and ascertain trends, including chi square tests for independence (followed by Cramer's $\mathrm{V}$ test to determine the strength of the association), analysis of variance (ANOVA) test, and independent sample t-tests. Where statistical significance was tested, the p-value was set at 0.5 . 
Karen E. McNamara et al.

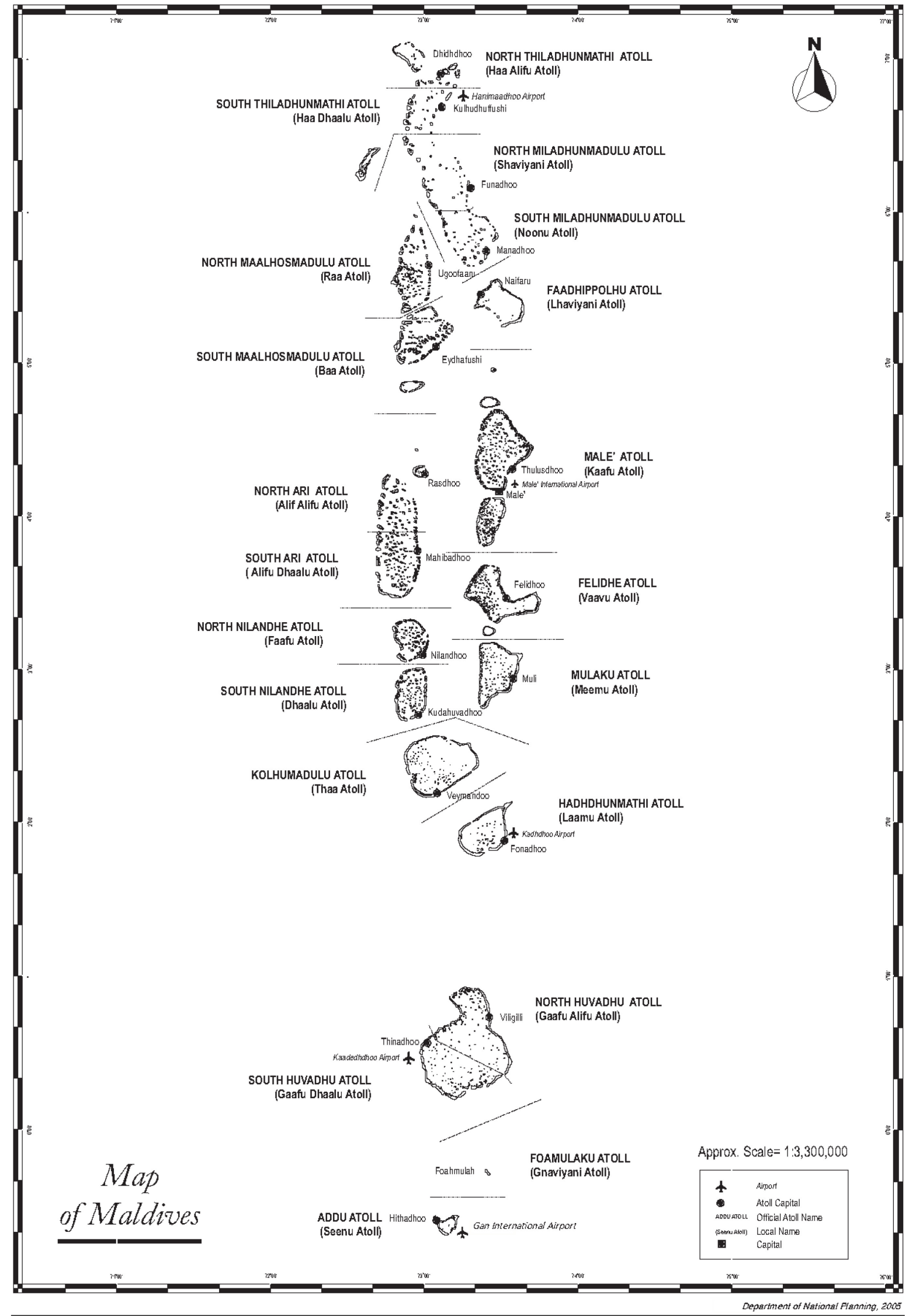

Figure 1: Map of the Maldives. C Department of National Planning, 2005. 
The focus of the study is Laamu Atoll, a southern coral atoll in the Maldives (Figure 1). As the second largest atoll in terms of land area, Laamu is comprised of 73 coral islands of which only 11 are inhabited by over 12,000 people (National Bureau of Statistics, 2014; UNDP, 2013). While a number of islands are reserved for particular industries, such as agriculture, fishing, or tourism, the majority are uninhabited. Population growth is relatively modest and density across the islands is non-uniform (UNDP, 2013). A number of general socioeconomic challenges exist across the atoll, including crime, drug abuse, limited access to services, and limited employment opportunities (UNDP, 2013, 2014). Due to its southcentral position, Laamu Atoll is exposed to multiple natural hazards such as floods, tropical storms, and droughts (UNDP, 2013).

The inhabited islands on Laamu have been disaggregated into three groups for analysis purposes (Figure 2). The islands Maavah, Maamendhoo, Kunahandhoo, and Hithadhoo form 'Group 1' and are located on the southwestern section of the atoll. Islands in the southeastern section (Gan and Fonadhoo) form 'Group 2', and the set of five islands at the northern end of the atoll (Isdhoo, Dhanbidhoo, Mundoo, Kalaidhoo, and Maabaidhoo) comprise 'Group 3'. These three island groupings are well-known and well-established across the atoll according to atoll council and UNDP staff. These island groups will be used in the following discussion to make comparisons between core islands (Group 2) and peripheral islands (Groups 1 and 3).

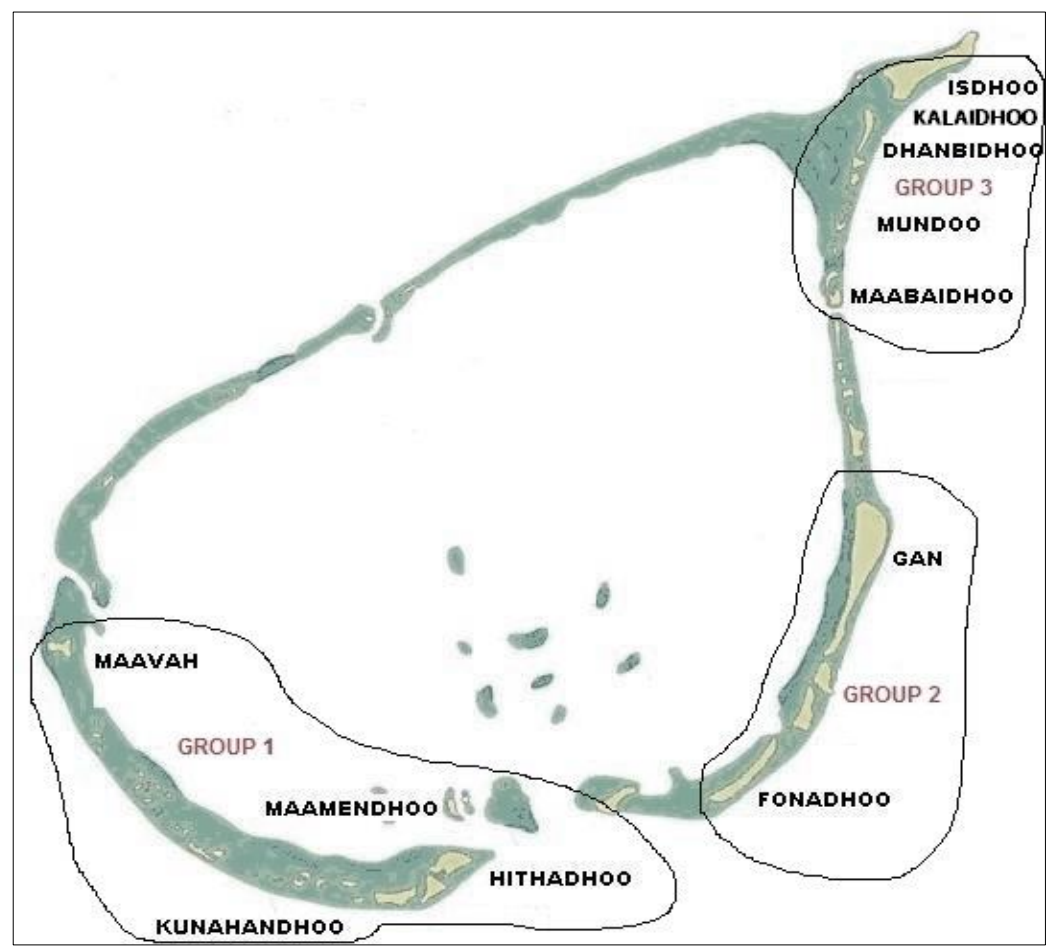

Figure 2: Islands and island groupings on Laamu Atoll. (C) UNDP, 2015 (island groupings done by authors).

\section{Results and discussion}

Overview of the sample

The majority of respondents were female (57.6\%) and aged between 35 and 44 years $(27.9 \%)$, followed by the 25-34-year age group (24\%). The majority of respondents were married (82.6\%) and most respondents had 3-5 children (39.1\%), followed by 1-2 (24.9\%), and 6-9 (21.1\%). Close to half of respondents (45.3\%) had 6-9 people living in their household, followed by $35.8 \%$ with 3-5 people. Almost all respondents were Maldivian citizens (99.5\%), 
with the remaining holding Indian citizenship. The majority of respondents were from Island Group 3 (40\%), followed by Group 1 (36\%) and Group 2 (24\%). The following sections examine some of the key determinants of vulnerability and explore what influences these factors.

Access to and quality of livelihood resources

The results revealed that 'access to medical facilities' and 'overall health' (both 2.81) yielded the overall lowest mean, followed by 'food access' (2.90), 'food quality' (2.97), 'water access' (3.09), and 'water quality' (3.17). Based on the analysis (ANOVA test) against identity, location, and income variables, only geography (location) revealed any statistically significant disparities in households' access/quality of livelihood resources (food quality [F=25.636, $\mathrm{p}=0.000]$, food access $[\mathrm{F}=16.617, \mathrm{p}=0.000]$, water quality $[\mathrm{F}=17.148, \mathrm{p}=0.000]$, water access $[\mathrm{F}=23.830, \mathrm{p}=0.000]$, overall health $[\mathrm{F}=6.040, \mathrm{p}=0.003]$, and access to medical facilities $[\mathrm{F}=4.868, \mathrm{p}=0.008])$. Out of the six livelihood resource indicators, Group 3 had the lowest ranking for five of them: food quality, food access, water quality, water access, and overall health (Figure 3). For the remaining indicator around access to medical facilities, peripheral islands in Group 1 received the lowest score, followed by Group 3, and were significantly lower than Group 2. Conversely, the core islands in Group 2 attained the highest score in all livelihood indicators except overall health in which it ranked second highest. These results indicate that, overall, Group 3 is the most vulnerable group of islands in terms of access to and quality of livelihood resources, while Group 2 (core islands) are better resourced. These results highlight the influence of location on the access to and quality of household livelihood resources which subsequently contributes to vulnerability.

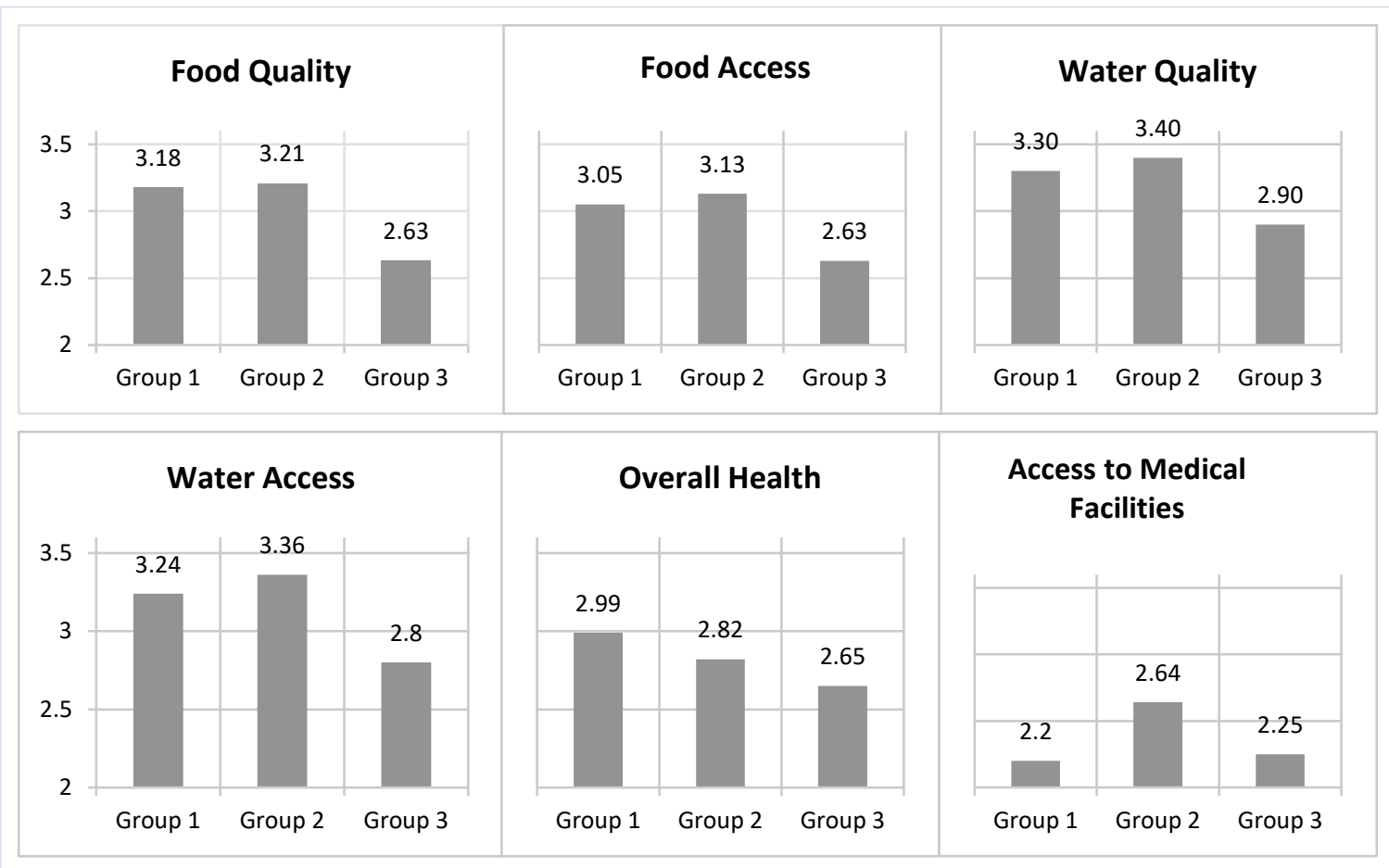

Figure 3. Mean levels of access to and quality of livelihood resources, compared across island groups.

The level of access to livelihood resources such as food and water across islands was also demonstrated through the likelihood of shortages. It was identified that peripheral islands in Group 1 were most vulnerable to experiencing a water shortage with $50 \%$ of respondents from Group 1 suffering from a water shortage as opposed to 29.9\% and 30.1\% from Groups 2 and 3 respectively. Alternatively, Group 3 was most vulnerable to experiencing a food shortage with $41.8 \%$ experiencing a food shortage compared to $5.6 \%$ and $15.7 \%$ in Groups 1 
and 2 respectively. Overall, Group 3 was the most susceptible to experiencing both a food and water shortage while the core islands were least likely to experience a food and/or water shortage. The relationship between island groups and experiencing shortages was identified as statistically significant using a chi square test for independence $\left(X_{2}=43.373, p=0.000\right.$; a Cramer's V value of 0.235 indicates that this is a moderate association). This pattern of inequality in resources and services between core and periphery islands reflects the aforementioned Core-Periphery Model (Friedmann, 1966) and has been identified as a nationwide trend in the Maldives (UNDP, 2014).

Population size is a crucial factor for service delivery in island settings as an island must reach a certain population threshold to be able to provide services locally (Fernandes \& Pinho, 2017). The lack of service delivery and access to certain resources in Groups 1 and 3 can also result in lower levels of socioeconomic well-being and is likely a result of a combination of difficulties. Difficulties include high transportation costs due to an inability to achieve economies of scale outside urban centres (Ghina, 2003), the restricted mobility between archipelagic islands to access services (Fernandes \& Pinho, 2017; Nunn, 2009), and the lack of government financial aid which results in those on the margin being excluded from infrastructure and service provision (Kumar, 2007).

Peripherality is a particular problem in the context of resources and services concentration as it can be self-perpetuating in SIDS where the appeal of urban centres can result in internal, peripheral-core migration which furthers island disparities in resources and service delivery, as well as urban primacy and associated vulnerabilities (Connell, 2007). This process reflects Myrdal's (1957) model of cumulative causation and spatial interaction where a core area with acquired advantages (such as improvements in infrastructure) will attract further investment, developments, and workers, thereby consistently remaining 'ahead' of other areas. Moreover, in the Maldives, this process of migration is encouraged as part of largely unpopular population and development consolidation policies that target development policies on a few regional islands and, through the incentives of improved social services and transportation networks, encourages relocation from peripheral areas (Kothari, 2014).

It is important to note that, although a dichotomy emerged between core islands (Group 2) and peripheral islands (Groups 1 and 3), differences between the peripheral islands groups also emerged. Group 1 followed closely behind the core islands across all indicators except overall health where it scored the highest and access to medical facilities where it scored the lowest. Therefore, Group 1, although composed of peripheral islands, reflected a lesser extent of vulnerability in the context of livelihood resources. This may reflect stage 3 in Friedmann's (1966) Core-Periphery Model's stages of development where, although focused on a national scale as opposed to an atoll scale, there is a predicted process of diffusion in which other growth centres or 'sub-centres' emerge as development benefits filter to peripheral areas. The consistently higher levels in resource access and quality and service quality in Group 1, therefore, may suggest the filtering of development benefits from core areas and Group 1's emergence as a sub-centre in Laamu Atoll. The movement away from a dichotomous core-periphery structure is also reflected in the World-systems theory where, although on a much larger scale, a 'semi-periphery' category was introduced to describe the intermediate and transitioning development state between the core and periphery (Wallerstein, 1974). Reynaud (1981) also recognised that not all regions will fit into a simple and dynamic dualistic scheme.

Although Group 2 consistently emerged as less vulnerable in the livelihoods context, findings for Group 2's food quality, food access, water quality, water access, and particularly access to medical facilities received scores closer to 'fair' as opposed to 'good' or 'very good'. It is important to recognise that the aforementioned 'nested core-periphery relations' may be relevant here as the 'core' islands in Group 2 are still peripheral to the country's capital, Malé (see UNDP, 2014) and to an external core beyond the country's borders (Weaver, 1998). 
Therefore, it may be expected that scores for Malé as the national core may be closer to the 'good' or 'very good' scores.

Group 3 emerged as most vulnerable in terms of the quality of and access to livelihood resources, followed by Group 1 and then Group 2. This was identified as broadly reflective of the Core-Periphery Model (Friedmann, 1966) as both groups of peripheral islands (Groups 1 and 3) emerged as more vulnerable than the core islands (Group 2). Although these findings indicate that Group 3 should be considered for most future policy interventions around livelihood resources, it is important to recognise that Group 1 still emerged as most vulnerable in some indicators (access to medical facilities and water shortages). Any future interventions should consider these differences.

\section{Financial security}

Under financial security, household income distribution across all island groups according to the four income brackets were $25.8 \%$ of households for less than MVR 4,999, 48.6\% for MVR 5,000-14,999, 17.5\% for MVR 15,000-24,999, and 8.2\% for more than MVR 25,000 . When disaggregated between island groups, Group 3 emerged as having the largest portion of respondents in the lowest income category and the lowest number of people in the higher income categories (Table 1). Conversely, Group 2 was identified as having the largest portion of respondents in the highest income group and the smallest number in the lowest income group. Statistical analysis using a chi square test for independence indicated that, across islands, statistical significance was found for monthly average income $\left(\mathrm{X}_{2}=54.560\right.$, $\mathrm{p}=0.000$; a Cramer's V value of 0.264 indicates that this is a moderate association).

Table 1: Monthly household income using four income brackets, across island groups.

\begin{tabular}{|c|c|c|c|c|}
\hline & Less than 4,999 & $5,000-14,999$ & $15,000-24,999$ & More than 25,000 \\
\hline Group 1 & $20.4 \%$ & $44.4 \%$ & $23.9 \%$ & $11.3 \%$ \\
\hline Group 2 & $6.5 \%$ & $60.2 \%$ & $20.4 \%$ & $12.9 \%$ \\
\hline Group 3 & $42.3 \%$ & $45.5 \%$ & $9.6 \%$ & $2.6 \%$ \\
\hline
\end{tabular}

For 'income satisfaction', the overall mean was 2.58 on the scale from 1 (not adequate for needs) to 5 (live comfortably with income). For 'money for emergencies' and 'community economic safety nets', the overall means were 2.05 and 2.19 respectively on the Likert scale between 1 (do not agree) and 5 (very strongly agree). For both income satisfaction and money for emergencies, Group 3 had the lowest scores while Group 2 had the highest scores. However, for the community economic safety nets indicator, Group 1 had the lowest mean, followed by Group 3 (Table 2). Using an ANOVA test, statistical significance was also found across islands for these financial indicators (income satisfaction $[\mathrm{F}=10.339, \mathrm{p}=0.000]$, money for emergencies $[\mathrm{F}=12.119, \mathrm{p}=0.000]$, and community economic safety nets $[\mathrm{F}=3.773$, $\mathrm{p}=0.025])$. Post Hoc testing revealed that statistical significance $(\mathrm{p}=0.005)$ was found between different Groups across the three indicators (Table 2). Analysing the five financial security indicators against identity, location, and income variables also showed that peripherality (as 'geography') was the only influential factor on financial security. 
Table 2: Financial indicators, across island groups.

\begin{tabular}{|c|c|c|c|}
\hline & Income satisfaction & $\begin{array}{l}\text { Money for } \\
\text { emergencies }\end{array}$ & $\begin{array}{l}\text { Community } \\
\text { economic safety nets }\end{array}$ \\
\hline Group 1 & $2.67^{a}$ & $2.08^{a}$ & $2.02^{a}$ \\
\hline Group 2 & $2.85^{b}$ & $2.66^{\mathrm{a}, \mathrm{b}}$ & $2.57^{\mathrm{a}, \mathrm{b}}$ \\
\hline Group 3 & $2.35^{\mathrm{a}, \mathrm{b}}$ & $1.72^{b}$ & $2.13^{b}$ \\
\hline
\end{tabular}

Therefore, across island groups, Group 3 emerged as the most financially vulnerable with the lowest means across three of the four indicators: monthly average income, income satisfaction, and money for emergencies. These were statistically significantly lower than Groups 2 and 1. Conversely, Group 2 attained the highest levels across all four indicators which suggest that core islands are the most financially secure. Additional statistics tests (independent sample t-tests) further reflected the role of peripherality, as geography, on the relationship between these four financial indicators and core (Group 2) and peripheral (combined Groups 1 and 3) islands (results showed statistical significance across all indicators: monthly average income $[\mathrm{t}=4.757, \mathrm{p}=0.000]$, income satisfaction $[\mathrm{t}=3.219, \mathrm{p}=0.001]$, money for emergencies $[\mathrm{t}=4.035, \mathrm{p}=0.000]$, and community economic safety nets $[\mathrm{t}=2.700$, $\mathrm{p}=0.008])$. These results, therefore, represent a statistically significant difference in financial vulnerability between core and peripheral islands and reflect a 'core bias' in which financial resources are concentrated in core/urban areas (Connell \& Lea, 1992). The resulting economic marginality of outer islands then intensifies vulnerability for these populations (Ribot, 1995). The lower levels in monthly income, satisfaction, and surpluses for emergencies in a peripheral setting can be a result of the penalties on growth associated with a lack of access to central markets and the narrow range of economic options (Sofer, 1985).

Limited financial resources in peripheral areas can also be a barrier to effective problemsolving in the context of climate change as well as the development of livelihood resources (Kumar, 2007; Nunn, 2009). Similar to the livelihood resources results, Group 1 appeared less vulnerable than Group 3 in the context of financial security, reflecting the previous discussion around Group 1's status as an emerging sub-centre.

It is important to note, however, that peripherality is not only characterised by disadvantages for outlying islands but encompasses implications on the sustainability and vulnerability of central areas as well (Fernandes \& Pinho, 2017). Core islands can, for example, also face difficulties stemming from the concentration of a disproportionate share of the population (Fernandes \& Pinho, 2017). This emerged in the context of Laamu Atoll where, when analysing the difficulty securing employment, core islands in Group 2 (mean=3.75) found it significantly more difficult to find and secure employment than Group 1 (3.11), and was higher (but not significantly) than Group 3 (3.43). Statistical significance (using an ANOVA test) was found between island groups and difficulty securing employment $(\mathrm{F}=4.984$, $\mathrm{p}=0.008$; Post Hoc testing revealed that statistical significance was found between Groups 1 and 2 [p=0.005], but not between any other Groups). Moreover, difficulty in securing employment was explored across other socio-demographic variables with no significant results, highlighting the role of location in influencing vulnerability in this context.

Therefore, although Group 2 encompassed the strongest financial security, there is also a greater difficulty in securing employment associated with location. This indicates how the core-periphery structure is unsustainable as a whole and can produce implications, albeit dissimilar, for the vulnerability and sustainability of both core and periphery areas (Fernandes 
\& Pinho, 2017). Moreover, assumptions around the incessant disadvantaged state of peripheral communities should be evaded through island-specific research that establishes urban and peripheral differences and uses these findings to inform policy and practice (Deidda, 2016).

The tests that were undertaken to ascertain whether there were significant differences in financial vulnerability across other identity variables and income showed no noteworthy findings, except in location. This highlights the key influence of location and peripherality on Laamu Atoll's financial security and its overall vulnerability. The importance of peripherality in an economic context has also been highlighted in proposed economic vulnerability indexes (e.g., Brigulio \& Galea, 2003; Crowards, 2000). According to these indexes, peripherality can contribute to economic vulnerability through increased exposure to economic shock and its impacts on transport and freight costs while generating marginalisation from core commercial centres (Brigulio, 2003).

Similarly to the earlier theme around livelihood resources, Group 3 emerged as most vulnerable in terms of financial security, followed by Group 1 and Group 2. It is, therefore, also recommended that future policy interventions around financial security target Group 3. Group 1 and Group 3, however, also had specific vulnerabilities where Group 1, for example, scored least in terms of access to community economic safety nets and Group 2 was most vulnerable in terms of securing employment. Any interventions specific to these indicators should target accordingly.

\section{Experiences of climate-change impacts}

Inter-island differences were also observed in terms of experiences of climate change and associated impacts. A total of $93.2 \%$ of respondents from Group 3 noticed a change in climate compared to Groups 1 and 2 in which $72.7 \%$ and $67.4 \%$, respectively, have experienced a change. Statistical tests indicated that whether or not respondents experienced climate change was moderately dependent on location, with Group 3 experiencing changes the most. Moreover, respondents from Group 3 had the highest percent of respondents who experienced livelihood impacts due to climate change $(57.4 \%)$, which was followed by Groups 2 (34.5\%) and 1 (24.1\%). Group 3 was identified as being most exposed to four out of seven identified climate hazards/impacts: tropical storms, droughts, tidal flooding, and changes in seasons (Figure 4).

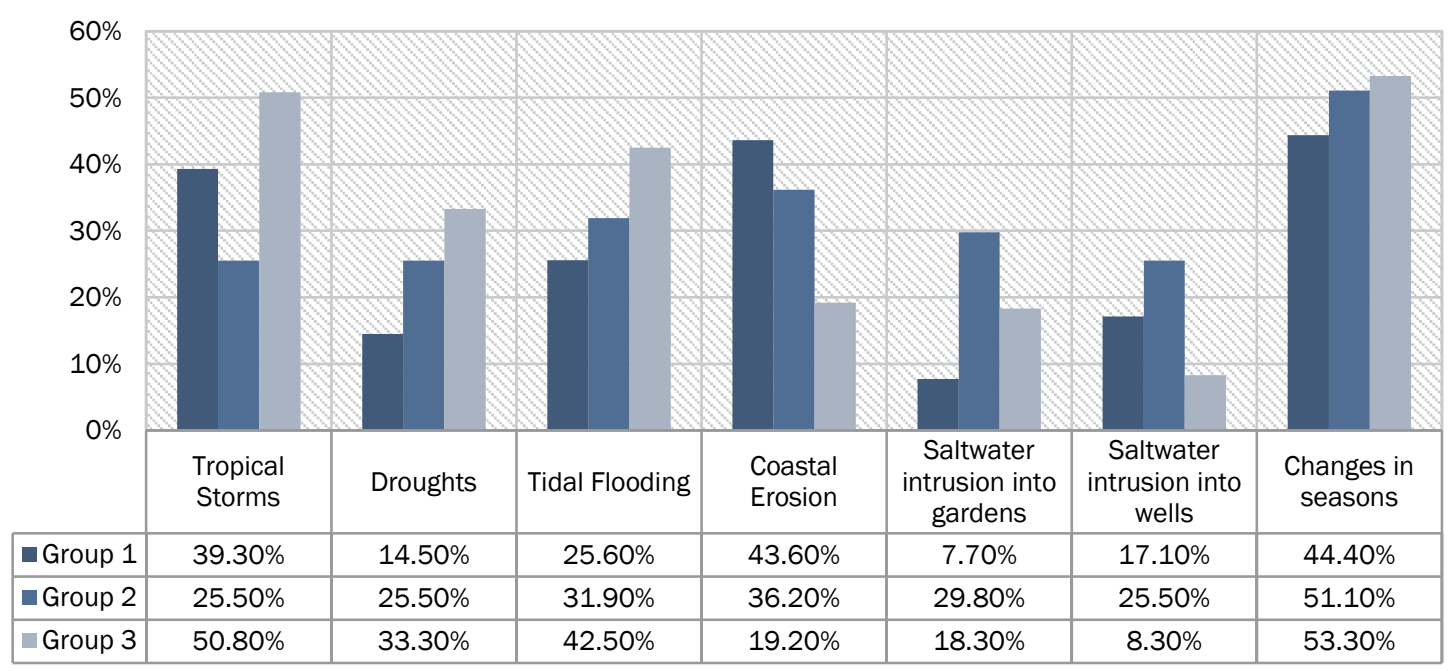

Figure 4: Respondents' exposure to climate hazards/impacts, across island groups.

This further highlights Group 3's elevated vulnerability. Exposure to and impacts from environmental hazards can also contribute to the aforementioned self-perpetuating nature of peripherality in SIDS where peripheral-core migration occurs and contributes to a widening 
disparity gap in terms of resources and services (Connell, 2007). Group 3's level of exposure is further exacerbated due to the specific hazards/impacts faced. For example, tropical storms and changes in seasons, to which Group 3 is most exposed, were identified as the hazards/impacts with the highest mean value (where $1=$ low to $3=$ high) for negative impact on households (mean=1.87 and 1.80 respectively) and the hardest to cope with (mean $=1.85$ and 1.78 respectively). Group 1 was most exposed to coastal erosion; however, it was least exposed to droughts, tidal flooding, saltwater intrusion into gardens, and changes in seasons. The core islands in Group 2 were identified as most exposed to saltwater intrusion into gardens and wells, which were also identified as having the smallest impact (mean=1.44 and 1.50 respectively) and being the least difficult hazards to cope with (mean=1.40 and 1.42 respectively). As shown in Figure 4, the peripheral islands of Group 3 emerged as the most exposed while Group 1 emerged as least exposed, based on respondents' perspectives. The significant influence of location on vulnerability in the context of climate-change exposure is furthered by the lack of association found across all other variables.

These inter-island differences in climate-change exposure may be a result of the influence that core-periphery structures have on the way climate-change solutions are understood and implemented (Kumar, 2007). It has been recognised that peripheral areas, comparatively to core areas, generally employ less appropriate climate solutions (i.e., inappropriately planned seawalls that have been observed in peripheral areas) due to the failures of central governments in reaching peripheral communities (Nunn, 2009; Nunn et al., 2014). Environmental decision-making is therefore conditioned largely by instinctive responses in peripheral areas (Nunn, 2009). Moreover, a core-periphery gradient in climatechange awareness has been identified in Pacific Islands which may, in combination with limited professional input, further contribute to ineffective adaptation responses and exacerbated exposure or vulnerability in peripheral areas (Kumar, 2007; Nunn et al., 2014; Nunn, 2009). This may explain the greater disruptions to livelihoods experienced and greater exposure among Group 3.

In terms of exposure to climate change, Group 3 emerged as the most exposed and the group that endures the greatest livelihood impact, followed by Group 2 and Group 1. Any funding towards climate-change adaptation in Laamu Atoll should, therefore, prioritise Group 3 then Group 2. The three groups also experience different types of hazards, which may be an important consideration. Future interventions, however, should not focus solely on hazards but should also consider or focus on previously discussed development challenges (Kelman, 2014).

\section{Conclusions}

Vulnerability has become a critical component of climate-change discourse and is most commonly thought to be influenced by socioeconomic and biophysical factors that affect a system's exposure, sensitivity, and adaptive capacity. As a low-lying SIDS country, understanding what shapes people's vulnerability to climate change in the Maldives is an integral part of planning efforts to safeguard and sustain populations. Focusing on Laamu Atoll in the south of the country, this study aimed to provide further understanding of vulnerability to climate change and provide a foundation for future vulnerability reduction initiatives. Household questionnaires $(n=412)$ collected across the atoll's inhabited islands revealed local perceptions on access to and quality of livelihood resources, financial security, and climatechange experiences. The data was then analysed according to a variety of characteristics to ascertain what might be shaping or influencing these vulnerability variables.

The findings demonstrate the key role of peripherality in influencing vulnerability in Laamu Atoll. This was evident through the lower levels of vulnerability in the core islands (Group 2) across all three themes. Securing employment (under financial security) was the only indicator where Group 2 emerged as most vulnerable, and Group 2 was also identified 
as more vulnerable than Group 1 in terms of exposure. Group 1 was identified as being a potential emerging sub-centre in alignment with theories around the diffusion of development benefits in core-periphery models as it predominantly emerged as less vulnerable than Group 3. Overall, Group 3 consistently emerged as most vulnerable across all themes. This study, however, was limited in terms of proxy indicators used and it is therefore recommended that future studies explore a wider range of factors that influence exposure, sensitivity, and adaptive capacity.

The consideration of peripherality and inter-island inequity in policy planning, design, and implementation has emerged as an overarching recommendation to ensure that differences in vulnerabilities are catered for and the exacerbation of existing disparities is avoided. The findings indicate that efforts to reduce vulnerabilities associated with livelihood resources and services, financial security, and exposure, as well as climate-change impacts on livelihoods, should be concentrated on the peripheral islands (Group 3) in Laamu Atoll. It is important to note, however, that any initiatives focusing on securing employment should be concentrated on Group 2 and any interventions focused on water shortages, access to community economic safety nets, and access to medical facilities should be focused on Group 1. This highlights the importance of informing policy through island-specific research and understanding core-periphery differences.

\section{Acknowledgements}

We are grateful to the participants for providing valuable insights in this study. We also wish to thank UNDP staff who were instrumental in organising fieldwork logistics, especially Umar Mavee. We are also grateful to the hard work of the data collectors in each of the islands, and also to the island council for their support of this study. This study was funded by UNDP as part of the LECReD project that is being piloted in Laamu Atoll.

\section{References}

Adger, W.N., Huq, S., Brown, K., Conway, D., \& Hulme, M. (2003). Adaptation to climate change in the developing world. Progress in Development Studies, 3(3), 179-195. https://doi.org/10.1191/1464993403ps060oa

Adger, W.N., \& Vincent, K. (2005). Uncertainty in adaptive capacity. Comptes Rendus Geoscience, 337(4), 399-410. https://doi.org/10.1016/j.crte.2004.11.004

Arnall, A., \& Kothari, U. (2015). Challenging climate change and migration discourse: different understandings of timescale and temporality in the Maldives. Global Environmental Change, 31, 199-206. https://doi.org/10.1016/j.gloenvcha.2015.01.011

Baldacchino, G. (2018). Seizing history: development and non-climate change in Small Island Developing States. International Journal of Climate Change Strategies and Management, 10(2), 217-228. https://doi.org/10.1108/IJCCSM-02-2017-0037

Barnett, J., \& Adger, W.N. (2003). Climate dangers and atoll countries. Climatic Change, 61(3), 321-337. https://doi.org/10.1023/B:CLIM.0000004559.08755.88

Becken, S., Hay, J., \& Espiner, S. (2011). The risk of climate change for tourism in the Maldives. In J. Carlsen \& R. Butler (Eds.) Island Tourism: Sustainable Perspectives (pp. 72-84). Wallingford, UK: CAB. https://doi.org/10.1079/9781845936792.0072

Behling, O., \& Law, K.S. (2000). Translating questionnaires and other research instruments. Thousand Oaks, CA: Sage. https://doi.org/10.4135/9781412986373

Betzold, C. (2015). Adapting to climate change in small island developing states. Climatic Change, 133(3), 481-489. https://doi.org/10.1007/s10584-015-1408-0

Birkmann, J., Cardona, O.D., Carre-o, M.L., Barbat, A.H., Pelling, M., Schneiderbauer, S., Kienberger, S., Keiler, M., Alexander, D., Zeil, P., \& Welle, T. (2013). Framing 
vulnerability, risk and societal responses: the MOVE framework. Journal of the International Society for the Prevention and Mitigation of Natural Hazards, 67(2), 193-211. https://doi.org/10.1007/s11069-013-0558-5

Blaikie, P., Cannon, T., Davis, I., \& Wisner, B. (1994). At risk: natural hazards, people's vulnerability and disasters. London: Routledge.

Blythe, J., Flaherty, M., \& Murray, G. (2015). Vulnerability of coastal livelihoods to shrimp farming: Insights from Mozambique. Ambio, 44(4), 275-284. https://doi.org/10.1007/s13280-014-0574-z

Briguglio, L. (2003). The vulnerability index and small island developing states: a review of conceptual and methodological issues. Paper presented to AIMS Regional Prepatory Meeting on the Ten Year Review of the Barbados Programme of Action. Praia, Cape Verde, September.

Briguglio, L.,\& Galea, W. (2003). Updating and augmenting the economic vulnerability index (Occasional Paper). Malta: Islands and Small States Institute, University of Malta.

Brooks, N., Adger, N.W., \& Kelly, M.P. (2005). The determinants of vulnerability and adaptive capacity at the national level and the implications for adaptation. Global Environmental Change, 15(2), 151-163. https://doi.org/10.1016/j.gloenvcha.2004.12.006

Connell, J. (2007). Migration. In G. Baldacchino (Ed.) A world of islands: an island studies reader (pp. 455-481). Charlottetown, PEI, \& Luqa, Malta: Island Studies Press.

Connell, J., \& Lea, J. (1992). My country will not be there: global warming, development and the planning response in small island states. Cities, 9(4), 295-309. https://doi.org/10.1016/0264-2751(92)90030-9

Crowards, T. (2000). An economic vulnerability index for developing countries, with special reference to the Caribbean: alternative methodologies and provisional results (Research Report). Barbados: Caribbean Development Bank.

Cutter, S.L., Boruff, B.J., \& Shirley, W.L. (2003). Social vulnerability to environmental hazards. Social Science Quarterly, 84(2), 242-261. https://doi.org/10.1111/1540-6237.8402002

Cutter, S. L., \& Finch, C. (2008). Temporal and spatial changes in social vulnerability to natural hazards. Proceedings of the National Academy of Sciences, 105(7), 2301-2306. https://doi.org/10.1073/pnas.0710375105

Deidda, M. (2016). Insularity and economic development: a survey. International Review of Economics, 63(2), 107-128. https://doi.org/10.1007/s12232-015-0238-8

Encontre, P. (1999). The vulnerability and resilience of small island developing states in the context of globalization. Natural Resources Forum, 23(3), 261-270. https://doi.org/10.1111/j.1477-8947.1999.tb00914.x

Fernandes, R., \& Pinho, P. (2017). The distinctive nature of spatial development on small islands. Progress in Planning, 112, 1-18. https://doi.org/10.1016/j.progress.2015.08.001

Folke, C. (2005). Resilience: the emergence of a perspective for social-ecological systems analyses. Global Environmental Change, 16(3), 253-267. https://doi.org/10.1016/j.gloenvcha.2006.04.002

Ford, J., \& Smit, B. (2004). A framework for assessing the vulnerability of communities in the Canadian Arctic to risks associated with climate change. Arctic, 57(4), 389-400. https://doi.org/10.14430/arctic516

Friedmann, J. (1966). Regional development policy: a case study of Venezuela. Cambridge, MA: MIT Press.

Füssel, H. (2010). How inequitable is the global distribution of responsibility, capability, and vulnerability to climate change: a comprehensive indicator-based assessment. Global Environmental Change, 20(4), 597-611. https://doi.org/10.1016/j.gloenvcha.2010.07.009

Füssel, H. (2007). Vulnerability: a generally applicable conceptual framework for climate change research. Global Environmental Change, 17(2), 155-167. https://doi.org/10.1016/j.gloenvcha.2006.05.002 
Füssel, H., \& Klein, R. (2006). Climate change vulnerability assessments: an evolution of conceptual thinking. Climatic Change, 75(3), 301-329. https://doi.org/10.1007/s10584-006-0329-3

Gallopin, G.C. (2006). Linkages between vulnerability, resilience and adaptive capacity. Global Environmental Change, 16(3), 293-303. https://doi.org/10.1016/j.gloenvcha.2006.02.004

Gay, J.C. (2014). Le réchauffement climatique: l'instrumentalisation des îles. L'Espace Geographique, 43(1), 81-89. https://doi.org/10.3917/eg.431.0081

Ghina, F. (2003). Sustainable development in small island developing states. Environment, Development and Sustainability, 5(1), 139-165. https://doi.org/10.1023/A:1025300804112

Hay, J. (2013). Small island developing states: coastal systems, global change and sustainability. Sustainability Science, 8(3), 309-326. https://doi.org/10.1007/s11625-013-0214-8

Heltberg, R., Siegel, P.B., \& Jorgensen, S.L. (2009). Addressing human vulnerability to climate change: toward a 'no-regrets' approach. Global Environmental Change, 19(1), 89-99. https://doi.org/10.1016/j.gloenvcha.2008.11.003

Hirsch, E. (2015). "It won't be any good to have democracy if we don't have a country": climate change and the politics of synecdoche in the Maldives. Global Environmental Change, 35, 190-198. https://doi.org/10.1016/j.gloenvcha.2015.09.008

Intergovernmental Panel on Climate Change (IPCC) (2014). Climate change 2014: Synthesis report, contribution of Working Groups I, II and III to the Fifth Assessment Report of the Intergovernmental Panel on Climate Change. https://doi.org/10.1017/CBO9781107415416

Intergovernmental Panel on Climate Change (IPCC) (2007). Climate change 2007: Synthesis report, contribution of Working Groups I, II and III to the Fourth Assessment Report of the Intergovernmental Panel on Climate Change. https://doi.org/10.1017/CBO9780511546013

Intergovernmental Panel on Climate Change (IPCC) (2001). Climate change 2001: Impacts, adaptation and vulnerability, contribution of Working Groups II to the Third Assessment Report of the Intergovernmental Panel on Climate Change. https://www.ipcc.ch/ipccreports/tar/wg2/index.htm

Joakim, E.P., Mortsch, L., \& Oulahen, G. (2015). Using vulnerability and resilience concepts to advance climate change adaptation. Environmental Hazards, 14(2), 137-155. https://doi.org/10.1080/17477891.2014.1003777

Kelman, I. (2018). Islandness within climate change narratives of small island developing states (SIDS). Island Studies Journal, 13(1), 149-166. https://doi.org/10.24043/isj.52

Kelman, I. (2014). No change from climate change: vulnerability and small island developing states. The Geographical Journal, 180(2), 120-129. https://doi.org/10.1111/geoj.12019

Khan, T.M.A., Quadir, D.A., Murty, T.S., Kabir, A., Aktar, F., \& Sarker, M.A. (2002). Relative sea level changes in Maldives and vulnerability of land due to abnormal coastal inundation. Marine Geodesy, 25(1-2), 133-143. https://doi.org/10.1080/014904102753516787

Kothari, U. (2014). Political discourses of climate change and migration: resettlement policies in the Maldives. Geographical Journal, 180(2), 130-140. https://doi.org/10.1111/geoj.12032

Kumar, R. (2007). Problems and prospects for islands at the margin: a case study of Moturiki Island, Central Fiji (Occasional Paper 47:41-50). Kagoshima: Kagoshima University Research Center for the Pacific Islands.

Kuruppu, N., \& Willie, R. (2015). Barriers to reducing climate enhanced disaster risks in Least Developed Country-Small Islands through anticipatory adaptation. Weather and Climate Extremes, 7, 72-83. https://doi.org/10.1016/j.wace.2014.06.001

Lata, S., \& Nunn, P.D. (2012). Misperceptions of climate-change risk as barriers to climatechange adaptation: a case study from the Rewa Delta, Fiji. Climatic Change, 110(1), 169-186. https://doi.org/10.1007/s10584-011-0062-4 
Lennox, E. (2015). Double exposure to climate change and globalization in a Peruvian highland community. Society \& Natural Resources, 28(7), 781-796. https://doi.org/10.1080/08941920.2015.1024364

Ludena C.E., \& Yoon, S.W. (2015). Local vulnerability indicators and adaptation to climate change: a survey (Technical Note No. 857). Washington, DC: Inter-American Development Bank.

Malatesta, S., \& Schmidt di Friedberg, M. (2017). Environmental policy and climate change vulnerability in the Maldives: from the 'lexicon of risk' to social response to change. Island Studies Journal, 12(1), 53-70. https://doi.org/10.24043/isj.5

Marshall, N.A., Stokes, C.J., Webb, N.P., Marshall, P.A., \& Lanester, A.J. (2014). Social vulnerability to climate change in primary producers: a typology approach. Agriculture, Ecosystems and Environment, 186, 86-93. https://doi.org/10.1016/j.agee.2014.01.004

McDowell, J.Z., \& Hess, J.J. (2012). Accessing adaptation: multiple stressors on livelihoods in the Bolivian highlands under a changing climate. Global Environmental Change, 22(2), 342-352. https://doi.org/10.1016/j.gloenvcha.2011.11.002

McGuirk, P.M., \& O’Neill, P. (2016). Using questionnaires in qualitative human geography. In I. Hay (Ed.) Qualitative research methods in human geography (pp. 246-273). Don Mills, Canada: Oxford University Press.

Moore, A. (2010). Climate changing small islands: considering social science and the production of island vulnerability and opportunity. Environment \& Society, 1(1), 116131. https://doi.org/10.3167/ares.2010.010106

Moss, R.H., Malone, E.L., \& Brenkert, A.L. (2001). Vulnerability to climate change: a quantitative approach (Report No. PNNL-SA-33642). Washington, DC: Joint Global Change Research Institute, Pacific Northwest National Laboratory.

Myrdal, G. (1957). Economic theory and underdeveloped regions. London, UK: Methuen.

National Bureau of Statistics (2014). Maldives: population and housing census. Malé: Ministry of Finance and Treasury. $\underline{\text { http://statisticsmaldives.gov.mv/nbs/wp- }}$ content/uploads/2015/10/Census-Summary-Tables1.pdf

Naseer, A. (1997). Status of coral mining in the Maldives: impacts and management options. Ministry of Fisheries and Agriculture. In D.J. Nickerson \& N. Hassan Maniku (Eds.) Workshop on integrated reef resources management in the Maldives. Madras, India: Bay of Bengal Programme. http://www.fao.org/docrep/X5623E/x5623e0o.htm

Nguyen, C., Horne, R., Fien, J., \& Cheong, F. (2017). Assessment of social vulnerability to climate change at the local scale: development and application of a social vulnerability index. Climatic Change, 143(3), 355-370. https://doi.org/10.1007/s10584-017-2012-2

Nunn, P.D. (2013). The end of the pacific? Effects of sea level rise on pacific island livelihoods. Singapore Journal of Tropical Geography, 34(2), 143-171. https://doi.org/10.1111/sjtg.12021

Nunn, P.D. (2009). Responding to the challenges of climate change in the Pacific Islands: management and technological imperatives. Climate Research, 40(2/3), 211-231. https://doi.org/10.3354/cr00806

Nunn, P., Aalbersberg, W., Lata, S., \& Gwilliam, M. (2014). Beyond the core: community governance for climate-change adaptation in peripheral parts of Pacific Island Countries. Regional Environmental Change, 14(1), 221-235. https://doi.org/10.1007/s10113-013-0486-7

Nurse, L.A., McLean, R.F., Agard, J., Briguglio, L.P., Duvat-Magnan, V., Pelesikoti, N., Tompkins, E., \& Webb, A. (2014). Small Islands. In V.R. Barros, C.B. Field, D.J. Dokken, M.D. Mastrandrea, K.J. Mach, T.E. Bilir, M. Chatterjee, K.L. Ebi, Y.O. Estrada, R.C. Genova, B. Girma, E.S. Kissel, A.N Levy, S. MacCracken, P.R. Mastrandrea \& L.L. White (Eds.) Climate change 2014: impacts, adaptation and vulnerability. Part B: Regional aspects (pp. 1613-1654). Cambridge, UK \& New York, USA: Cambridge University Press. https://www.ipcc.ch/publications and data/ar4/wg2/en/ch16.html

Patton, M.Q. (2002). Qualitative research and evaluation methods. Thousand Oaks, CA: Sage. 
Pelling M., \& Uitto, J.I. (2001). Small island developing states: natural disaster vulnerability and global change. Environmental Hazards, 3(2), 49-62. https://doi.org/10.3763/ehaz.2001.0306

Reynaud, A. (1981). Société, espace et justice. Inégalités regionals et justice socio-spatiale. Paris: Presses Universitaires de France. https://doi.org/10.3917/puf.reyna.1981.01

Ribot, J. (2014). Cause and response: vulnerability and climate in the Anthropocene. Journal of Peasant Studies, 41, 667-705. https://doi.org/10.1080/03066150.2014.894911

Ribot, J. (1995). The causal structure of vulnerability: its application to climate impact analysis. GeoJournal, 35(2), 119-122. https://doi.org/10.1007/BF00814058

Shakeela, A., \& Becken, S. (2015). Understanding tourism leaders' perceptions of risks from climate change: an assessment of policy-making processes in the Maldives using the social amplification of risk framework (SARF). Journal of Sustainable Tourism, 23(1), 6584. https://doi.org/10.1080/09669582.2014.918135

Smit, B., \& Wandel, J. (2006). Adaptation, adaptive capacity and vulnerability. Global Environmental Change, 16(3), 282-292. https://doi.org/10.1016/j.gloenvcha.2006.03.008

Sofer, M. (1985). The dependency paradigm applied to the Fijian periphery. Singapore Journal of Tropical Geography, 6(3), 127-138. https://doi.org/10.1111/j.1467-9493.1985.tb00166.x

Sovacool, B. (2012). Perceptions of climate change risks and resilient island planning in the Maldives. Mitigation and Adaptation Strategies for Global Change, 17(7), 731-752. https://doi.org/10.1007/s11027-011-9341-7

Stratford, E., Baldacchino, G., McMahon, E., Farbotko, C., \& Harwood, A. (2011). Envisioning the archipelago. Island Studies Journal, 6(2), 113-130.

United Nations (UN) (2012). The future we want. Rio de Janeiro: United Nations.

United Nations (UN) (1992). Agenda 21. Rio de Janeiro: United Nations.

United Nations Development Programme (UNDP) (2014). Maldives human development report 2014, bridging the divide: addressing vulnerability, reducing inequality. Maldives: Ministry of Finance and Treasury and the United Nations Development Programme.

United Nations Development Programme (UNDP) (2013). Low emission climate resilient development joint programme document. Maldives: United Nations Development Programme.

United Nations - Office of the High Representative for the Least Development Countries, Landlocked Developing Countries and Small Island Developing States (UN-OHRLLS) (n.d.). About SIDS - country profiles. http://unohrlls.org/about-sids/country-profiles/

Wadey, M., Brown, S., Nicholls, R.J., \& Haigh, I. (2017). Coastal flooding in the Maldives: an assessment of historic events and their implications. Natural Hazards, 89(1), 131-159. https://doi.org/10.1007/s11069-017-2957-5

Wallerstein, I. (1974). The modern world system I: capitalist agriculture and the origins of the European world economy in the sixteenth century. New York: Academic Press.

Weaver, D.B. (1998). Peripheries of the periphery: tourism in Tobago and Barbuda. Annals of Tourism Research, 25(2), 292-313. https://doi.org/10.1016/S0160-7383(97)00094-7

Weis, S.W.M., Agostini, V.N., Roth, L.M., Gilmer, B., Schill, S.R., Knowles, J.E., \& Blyther, R. (2016). Assessing vulnerability: an integrated approach for mapping adaptive capacity, sensitivity, and exposure. Climatic Change, 136(3), 615-529. https://doi.org/10.1007/s10584-016-1642-0

Wisner, B., Blaikie, P., Cannon, T., \& Davis, I. (2004). At risk natural hazards, people's vulnerability and disasters. London, UK: Taylor \& Francis. 